\title{
A TRAJETÓRIA ACADÊMICA E CIENTÍFICA DO PROF. PONTES
}

Em 26 de dezembro de 2005 faleceu, aos 90 anos, o Prof. José Fernandes Pontes.

A Gastroenterologia sofreu uma grande perda.

Nascido em Espírito Santo do Pinhal, Estado de São Paulo, em 24 de fevereiro de 1915, depois De freqüentar o curso secundário no Liceu Rio Branco e complementar no antigo Colégio Universitário, ingressou, em 1935, na Faculdade de Medicina da Universidade de São Paulo, onde se graduou em 1940. Essa turma de 82 formandos consagrou-se por produzir forte densidade de grandes luminares da nossa Medicina, como: Michel Abu Jamra, Alberto Carvalho da Silva, Rui Ferreira Santos, Carlos da Silva Lacaz, Mozart Tavares de Lima Filho, Henrique Mélega, Júlio Kieffer, Octávio Germeck, Alvaro Dino de Almeida, Luiz Gustavo Wertheimer, Marino Lazzareschi, Gulherme Curban, Helio Lourenço de Oliveira, Ennio Botelho Perrone, José de Arruda Botelho, Oswaldo Mellone, José Maria Ferreira, Walter Bomfim Pontes, todos com rica biografia como foi a do Prof. José Fernandes Pontes.

Seu pendor para a especialidade nasceu em 1940, quando estagiário do Ambulatório de Gastroenterologia da Santa Casa de São Paulo, chefiado pelo Dr. Levy Sodré, onde elaborou seu primeiro trabalho sobre Amebíase, publicado com Jamra M, e Silva AC.

Defendeu sua Tese de Doutoramento em janeiro de 1947 e imediatamente, em maio do mesmo ano realizou o concurso de Livre-Docência em Clínica Médica.

Em 19 de abril de 1944, as cadeiras clínicas instaladas na Santa Casa de São Paulo foram transferidas para o novel Hospital das Clínicas. Com o apoio dos Prof. Cantídio de Moura Campos e Benedito Montenegro e do Dr. Alberto Carvalho da Silva, Assistente da Cátedra de Fisiologia do Prof. Franklin de Moura Campos, criou pequeno laboratório no $9^{\circ}$ andar - na $3^{\text {a }}$ Clínica Cirúrgica - depois transferido para a Cátedra de Terapêutica Clínica - na sala 3025 do $3^{\circ}$ andar. Esse Serviço expandiu-se, ganhando espaço e novos membros, sendo oficializado pela Administração do Hospital das Clínicas em 5 de maio de 1949. Com forte apoio do Prof. Cantídio, aí criou o consistente Grupo de Gastroenterologia, graças a sua força aglutinadora, espírito de dedicação, determinismo e as suas relações sociais e empresariais, de quem obteve muito suporte econômico para criar laboratórios modernamente equipados para análises clínicas e pesquisas.

Dentro do Hospital das Clínicas, foi pioneiro em criar setores para estudos e pesquisas, unindo os componentes em grupos: esôfago, estômago e duodeno (José de Souza Meirelles Filho e Agostinho Bettarello), intestino delgado e cólons (José Vicente Martins Campos), Proctologia (José Tiago Pontes), pâncreas e absorção intestinal (Dirceu Pfuhl Neves), vias biliares (Vinício P. Conte), fígado e circulação portal (Luiz Caetano da Silva), Medicina Psicossomática (Heladio Francisco Capisano), Peritonioscopia e Laparofotografia (Mitja Polak), Laboratório Clínico (Waldemar Podolsky, João O. Martinez, Henrique Elkis e Wolfgang Rothstein), funções gerais (Scharif Kurban, Arnaldo de Godoy e Naum Kusminski).

Foram também seus estagiários, jovens médicos que se tornaram nomes de grande destaque na Medicina brasileira, como Roberto Santos, Luiz Rachid Trabulsi, Wilhelm Kenzler, Alvaro Oscar Campana, Naum Kusminsky, Jayme Scherb, Luiz de Paula Castro, Jeronimo Martins Andrade, Claudio Montenegro Castelo Branco, Gilberto Rebouças, Edesio Rocha Barreto, Milton Pecis Abramovich, Henrique Elkis, José Aristodemo Pinotti, entre muitos outros. No exterior, destacaram-se: Hernan Espejo Romero do Peru e Miguel Marchese de Buenos Aires.

Essa verdadeira escola realizou inúmeros e importantes trabalhos em todos os setores da Gastroenterologia. Publicou estudos marcantes que tiveram grande influência no progresso da Gastroenterologia. O Prof. Pontes conta com inúmeros seguidores em todos os quadrantes do País também criadores de pólos que promoveram o progresso da especialidade.

Sua esposa, dona Lélia, teve importante papel como companheira solidária de todos os momentos.

Prof. Henrique Walter PINOTTI*

* Professor Emérito da Universidade de São Paulo. 